\title{
Enhancement of antibody-dependent cellular cytotoxicity is associated with treatment response to extracorporeal photopheresis in Sézary syndrome
}

\author{
Christoph Iselin ${ }^{a}$, Yun-Tsan Chang a,b , Tanja Schlaepfer ${ }^{c}$, Christina Fassnacht $\mathbb{D}^{\mathrm{a}, \mathrm{d}}$, Florentia Dimitriou ${ }^{\mathrm{a}}$, Mirjam Nägeli $\mathbb{D}^{\mathrm{a}}$, \\ Steve Pascolo (D) ${ }^{a}$, Wolfram Hoetzenecker ${ }^{\mathrm{d}}$, Malgorzata Bobrowicz (D) ${ }^{\mathrm{e}}$, and Emmanuella Guenova (D) ${ }^{\mathrm{a}, \mathrm{b}}$ \\ aDepartment of Dermatology, University Hospital Zurich, University of Zurich, Zurich, Switzerland; bDepartment of Dermatology, Lausanne University \\ Hospital CHUV, University of Lausanne, Lausanne, Switzerland; 'Department of Dermatology, Cantonal Hospital St. Gallen, St. Gallen, Switzerland; \\ dDepartment of Dermatology, Kepler University Hospital, Linz, Austria; 'Department of Dermatology, Lausanne University Hospital CHUV and Faculty \\ of Biology and Medicine, Lausanne University, Lausanne, Switzerland
}

\begin{abstract}
Summary
Sézary syndrome (SS) is a rare, leukemic type of cutaneous T-cell lymphoma (CTCL), for which extracorporeal photopheresis (ECP) is a first-line therapy. Reliable biomarkers to objectively monitor the response to ECP in patients with SS are missing. We examined the quantitative and qualitative impact of ECP on natural killer (NK) cell activity in SS patients, and especially their functional ability for antibodydependent cell-mediated cytotoxicity (ADCC). Further, we addressed the question whether the magnitude of the effect on ADCC can be associated with the anti-cancer efficacy of ECP in SS patients. We assessed numbers of NK cells, ADCC activity, and treatment response based on blood tumor staging in a cohort of 13 SS patients ( 8 women, 5 men) treated with ECP as a first-line therapy. Blood samples were collected before treatment start and after an average of 9 months of uninterrupted ECP treatment. NK cell numbers were reduced in SS patients compared to healthy individuals and showed a tendency of recovery after long-term ECP treatment, independent of the clinical response to treatment. Patients with marginal increase ( $\leq 1.5 \mathrm{AU}$-fold) or lack of increase in ADCC activity failed to respond clinically to treatment, while patients with an increased ADCC activity showed a reduction in blood tumor burden. NK-mediated ADCC is selectively enhanced and might be a mechanism underlying the effect of ECP while in addition it can possibly serve as a reliable biomarker to objectively monitor response to ECP in patients with SS.
\end{abstract}

\section{ARTICLE HISTORY}

Received 4 November 2020

Revised 4 January 2021

Accepted 6 January 2021

\section{KEYWORDS}

Cutaneous T cell lymphoma; Sézary syndrome; mycosis fungoides; dermatology; extracorporeal photophoresis; cellular cytotoxicity; biomarker; treatment response

\section{Introduction}

Sézary syndrome (SS) is a rare leukemic type of cutaneous T-cell lymphoma (CTCL) representing around 5\% of all CTCL cases. ${ }^{1,2}$ SS typically manifests with a triad of erythroderma, generalized lymphadenopathy, and the presence of malignant $\mathrm{T}$ cells in the skin, lymph nodes, and peripheral blood, morphologically presenting with "cerebriform" nuclei. $^{3,4}$ Numerous immune abnormalities have been described in SS patients, most commonly reported among those are the increased secretion of immunosuppressive Th2 cytokines and the decreased proinflammatory Th1-mediated immune response..$^{5-7}$ These alterations lead to global immunosuppression and increased susceptibility to infections which are a leading cause of death in SS patients. ${ }^{8}$ Therefore, therapeutic approaches that aim at immune modulation are standard therapies in SS. Currently, extracorporeal photophoresis (ECP) and administration of interferon- $\alpha$, are established and recommended first-line immunomodulatory treatment options in SS. ${ }^{1}$ ECP is a leukapheresis-based therapy, where the patient's lymphocytes are collected and exposed to methoxsalen followed by ultraviolet A light, before being reinfused to the patient. ECP is nowadays available in more than 200 centers worldwide with cited response rates for CTCL of approximately $60 \%$ and complete responses of $14-26 \% .{ }^{9,10}$ ECP is used as a monotherapy or in combination with other immunomodulatory agents, and is well-tolerated. ${ }^{10,11}$ Given the interpatient variability of reponse to ECP, the identification of factors associated with a positive response to ECP at baseline is of great interest.

In this work, we aimed to answer the question whether ECP influences the number of NK cells and the efficacy of NKmediated antibody-dependent cellular cytotoxicity (ADCC). ADCC is an adaptive immune response, where Fc receptorbearing NK cells recognize and kill antibody-coated target cells by releasing cytotoxic molecules, such as perforin and granzymes. Furthermore, we aimed to explore if the magnitude of ADCC can be associated with the treatment response in SS patients.

\section{Materials and methods}

\section{Patients and collection of primary human samples}

13 patients newly diagnosed with Sézary syndrome between 2012 and 2019 treated with ECP as a first-line systemic monotherapy with at least 1.5 months clinical follow-up after the start of the ECP therapy were included in a single-center,

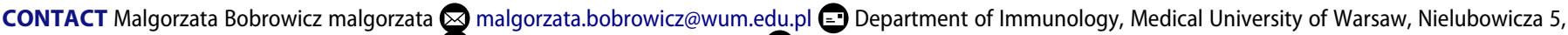

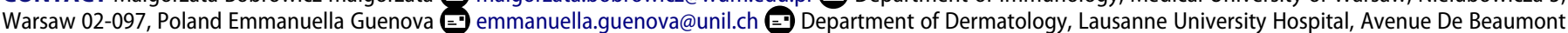
29, Lausanne $\mathrm{CH}-1011$, Switzerland. 
retrospective, cohort study (Table 1). Diagnosis of Sézary syndrome was established according to the criteria of the World Health Organization-European Organization for Research and Treatment of Cancer and the International Society for Cutaneous Lymphomas. ${ }^{4,12}$ ECP treatment was performed using the closed photopheresis apparatus "CELLEX"
(Mallinckrodt Pharmaceuticals, USA). Treatment schedule followed the European dermatology forum-guidelines on the use of extracorporeal photophoresis, with one ECP cycle (on two consecutive days) every 2 weeks for the first 3 months, followed by one ECP cycle every 4 weeks. ${ }^{9}$ The peripheral blood samples were collected during routine ECP procedure right before the

Table 1. Clinical patients' characteristics.

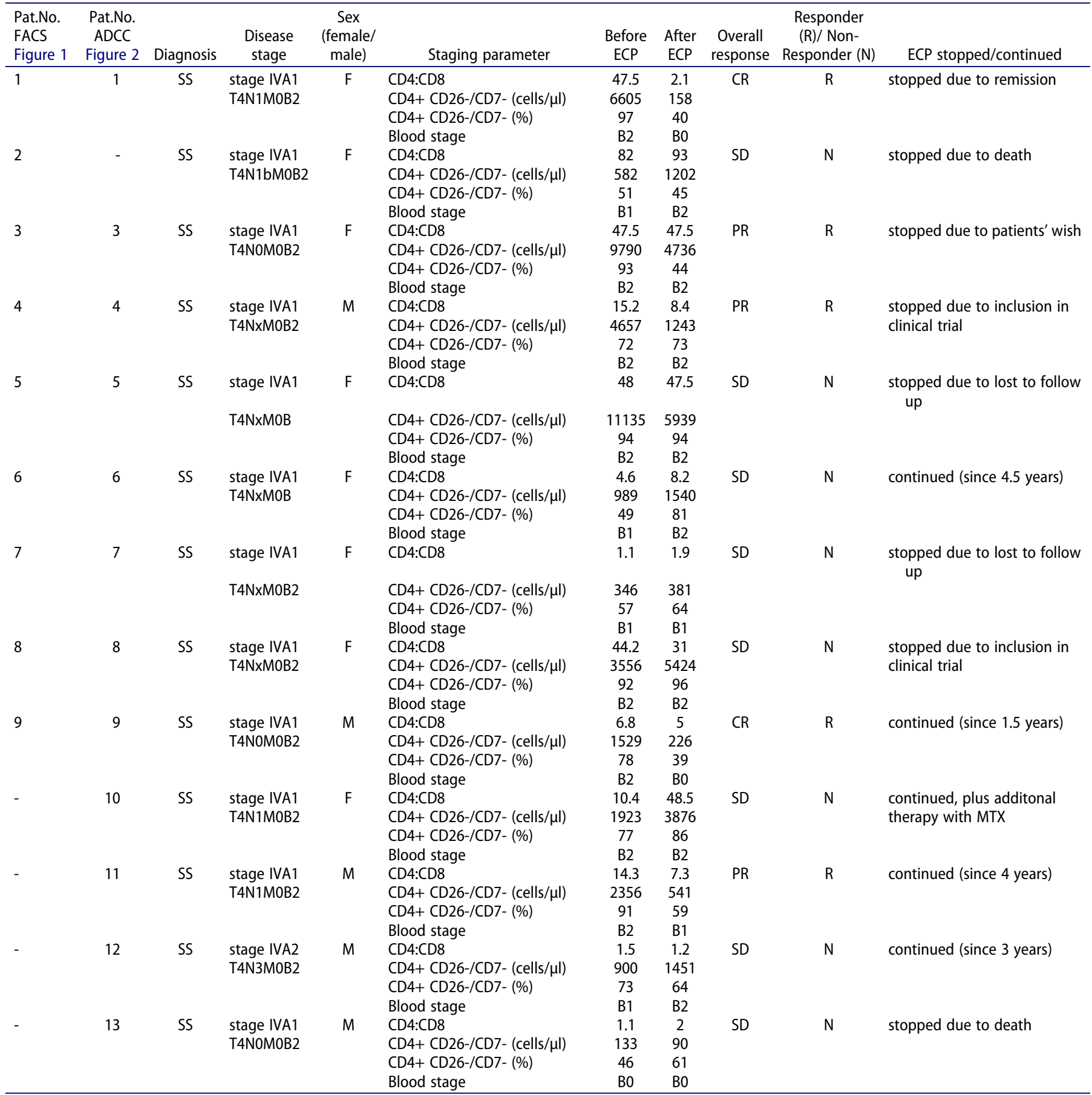

MTX: Methotrexate

Responder: $\mathrm{CR}, \mathrm{PR}$

Non-responder: SD, PD

SS: Sezary Syndrome

ECP: Extracorporeal photopheresis

CR: complete response

PR: partial response

SD: stable disease

PD: progressive disease 
initiation of ECP treatment and on average after 9 months of uninterrupted ECP treatment. In detail, $69.2 \%(9 / 13)$ of the baseline pre-ECP samples were collected within 2 days before ECP initiation, $30.7 \%(4 / 13)$ samples were collected at a median of 2.5 months (range 1-7) before therapy start. $61.5 \%(8 / 13)$ of the post-ECP samples were collected after a median of 6.75 months (range $1.5-9$ months), and $38.5 \%$ of the samples were from patients on long-term ECP and were collected after a median of 13 months (range 12-26 months). Blood samples from healthy individuals served as control where indicated. Peripheral blood from the patients was collected in the context of the University of Zürich Biobank, funded by the University of Zurich University Research Priority Program (URPP) in translational cancer biology. All patients signed an informed consent agreeing to the use samples, including the generation of cell cultures according to the Biobank project (EK No. 647). Blood from healthy individuals was obtained anonymously from the blood bank of the University Hospital Zurich. The study was conducted in accordance with the principles of the Declaration of Helsinki and was approved by the Institutional Review Board of the Canton of Zurich (KEK-ZH-No. 2015-0209).

\section{Clinical evaluation and response criteria}

Assessment of clinical response to treatment was done according to the consensus statement of the International Society for Cutaneous Lymphomas (ISCL), the United States cutaneous lymphoma consortium, and the cutaneous lymphoma task force of the European Organization for Research and Treatment of Cancer (EORTC). ${ }^{13}$ Briefly, patients that reached $\mathrm{B} 0$ under therapy were considered in complete remission (CR). Partial remission (PR) was defined as $>50 \%$ decrease in quantitative measurements of blood tumor burden from baseline in those with high tumor burden at baseline $\left(\mathrm{B}_{2}\right)$. Progressive disease $(\mathrm{PD})$ was defined as $>50 \%$ increase from baseline and at least 5,000 neoplastic cells/ $\mu$ l blood. Stable disease (SD) includes patients that fail to attain criteria for CR, PR, or PD. For the current analysis, patients with CR or PR were considered "responders" and patients with SD or PD as "non-responders" to ECP treatment.

\section{Isolation of human peripheral blood mononuclear cells (PBMCs) and cell lines}

Patient's peripheral blood mononuclear cells (PBMCs) were isolated by Ficoll density gradient centrifugation. Raji, a Burkitt's lymphoma cell line was a kind gift from Prof. Magdalena Winiarska, Department of Immunology, Medical University of Warsaw.

\section{Flow cytometry}

To assess the percentage of NK cells in the collected PBMCs, the samples were analyzed by flow cytometry using anti-human monoclonal antibodies: CD3 (clone BW264/56, PerCP; Miltenyi Biotec \#130-096-910), CD4 (Clone VIT4; label APCVio770; Miltenyi Biotec \# 130-098-153), CD8 (clone RPA-T8, PE; Beckton Dickinson) and CD56 (clone AF12-7H3, PEVio770; Miltenyi Biotec \#130-096-831). Samples were acquired on Becton Dickinson, Allschwil, Switzerland FACSCanto II instrument. Flowjo V 10.0.8r1, Becton Dickinson and Company, Franklin Lakes, NJ, USA, Origin Pro 2017, Northampton, MA, USA and GraphPad Prism 5.0 Software, San Diego, CA, USA were used for data analysis and statistics.

\section{Antibody-dependent cellular cytotoxicity assay}

To assess NK cell activity in primary human samples, we resuspended the PBMCs in $5 \mathrm{ml}$ cRPMI 1640 supplemented with $100 \mathrm{IU} / \mathrm{ml}$ IL-2 (manufactured by ourselves using humanIL-2-transfected J558 cells) and $10 \mathrm{ng} / \mathrm{ml}$ Il-15 (\#200-15 Peprotech, Rocker Hill, USA) and incubated them on 6-well plates for $24 \mathrm{~h}\left(37^{\circ} \mathrm{C}, 5 \% \mathrm{CO}_{2}\right)$. After 24 hours, the samples were centrifuged (1200 rpm, 3 min RT), resuspended with $1 \mathrm{~mL}$ RPMI 1640, counted, adjusted to a concentration of $4^{\star} 10^{6}$ cells $/ \mathrm{ml}$ and used in ADCC assay as effector PBMCs. For the ADCC assay, cells from the CD20-expressing Raji cell line, maintained in $\mathrm{CRPMI}$ at $37^{\circ} \mathrm{C}, 5 \% \mathrm{CO}_{2}$, were adjusted to a final concentration of $2^{\star} 10^{5}$ cells $/ \mathrm{ml}$ and $25 \mu$ of the Raji cellcontaining solution was seeded on a 96 well plate. $25 \mu \mathrm{l}$ of the anti-human CD20 monoclonal antibody Rituximab (RTX, \#B6097, Roche, Basel, CH) at a concentration of $300 \mu \mathrm{g} / \mathrm{ml}$ (Raji 100), $30 \mu \mathrm{g} / \mathrm{ml}$ (Raji 10) or $0 \mu \mathrm{g} / \mathrm{ml}$ (Raji 0 ) was added and the cells were incubated in $37^{\circ} \mathrm{C}$ for $15 \mathrm{~min}$ to enable surface labeling with the antibody. Finally, $25 \mu \mathrm{l}$ of the effector PBMCs $\left(4^{\star} 10^{6}\right.$ cells $\left./ \mathrm{ml}\right)$ were added, the plates were centrifuged $(3 \mathrm{~min}$, $750 \mathrm{rpm}, \mathrm{RT}$ ) and incubated at $37^{\circ} \mathrm{C}, 5 \% \mathrm{CO}_{2}$ for 4 hours. The cell lysis was quantified by the amount of lactate dehydrogenase $(\mathrm{LDH})$ released into the culture supernatant and measured with a commercially available kit according to the manufacturer's instructions (Pierce ${ }^{\mathrm{Tw}}$ LDH Cytotoxicity Assay Kit; 88953, ThermoFisher, Waltham, USA). Maximum LDH release was determined by lysis in $0.2 \%$ Triton X-100. All experiments were performed in triplicates. $\mathrm{LDH}$ release was detected at $490 \mathrm{~nm}$ (LDH measurement) and $630 \mathrm{~nm}$ (background) using a microplate reader (ELx808 Absorbance Reader; BioTek; Winooski, USA). The effective ADCC in arbitrary units (AU) was calculated as the ratio between $\mathrm{LDH}$ absorption in the presence of $100 \mu \mathrm{g} / \mathrm{ml} \mathrm{RTX}$ and in the absence of RTX [ADCC [AU] =].

\section{Statistical analysis}

Data were tested for normal distribution with Shapiro-Wilk test. Dependent on the distribution pattern, Mann Whitney test for unpaired, not normally distributed sample groups and Wilcoxon matched pairs signed rank test for paired, not normally distributed sample groups. $P$ values $\leq 0.05$ were considered significant. Statistical calculations were done on GraphPad Prism ${ }^{\circledR} 7.01$ software.

\section{Results}

\section{NK cell numbers are reduced in SS patients compared to healthy individuals}

In graft-versus-host disease (GvHD) patients for whom ECP therapy is commonly used, ECP treatment affects the NK cell 
compartment, ${ }^{14}$ and an increase of the CD56 ${ }^{\text {bright }} \mathrm{NK}$ subset is predictive of response to treatment. ${ }^{15}$ To study the role of NK cells in the response in SS patients, we first assessed NK cell number in peripheral blood of SS patients compared to healthy individuals by flow cytometry. At baseline, we detected a significant decrease in $\mathrm{CD}^{-}$and $\mathrm{CD}^{-} 6^{+} \mathrm{NK}$ cell numbers (gating strategy shown in Figure 1a) in SS patients with a median of $92 \mathrm{cell} / \mu \mathrm{l}$ as compared to healthy individuals with a median of 238 cell/ $\mu$ l ( $p$ value: 0,00045 ) (Figure $1 b)$. To study the effect of ECP, we compared the NK cell numbers at initiation of ECP treatment and after an average of 9 months of uninterrupted ECP in a cohort of nine SS patients (Table 1). Following ECP, we detected a slight increase of total CD56 ${ }^{+}$ NK cells (Figure 1c), as well as of the CD56 ${ }^{\mathrm{dim}}$ (Figure 1d) and CD56 ${ }^{\text {bright }}$ (Figure 1e) NK cell subsets with great interpatient variability. Although we observed a general tendency of recovery of diminished NK cell subsets in SS patients on long-term ECP treatment, none of the reported quantitative changes reached statistical significance or could be associated with the treatment response (Figure 1c-f).

\section{$A D C C$ is enhanced in ECP responders}

The quality of the NK cell activity might be a positive response predictor for ECP. ${ }^{16}$ As antibody-dependent cellular cytotoxicity (ADCC) is a major effector function of $\mathrm{NK}$ cells, ${ }^{17}$ we evaluated its efficacy in SS patients before and after long-term ECP treatment. While a standard $\mathrm{LDH}$ release assay revealed no significant difference in the ADCC efficacy in SS patients at baseline (mean $1.087 \mathrm{AU}$ ) compared to healthy individuals (mean 1.25 AU) (Figure 2a), there was a significant increase in the ADCC efficacy in SS patients upon long-term uninterrupted ECP treatment (mean 2.28 AU ( $p=.004)$ (Figure 2a). In general, at a threshold of $\geq 1.5 \mathrm{AU}$-fold, the efficacy of ADCC was increased in $41.66 \%(5 / 12)$ of all ECP treated SS patients (Figure 2b). When stratified according to their clinical response to ECP treatment, all but one of the patients with increased ADCC upon treatment $\geq 1.5$ AU-fold responded clinically, while patients with marginal increase $(\leq 1.3 \mathrm{AU}$ fold) or lack of increase in ADCC activity failed to respond to ECP treatment (Figure 2c). Furthermore, the overall level of a
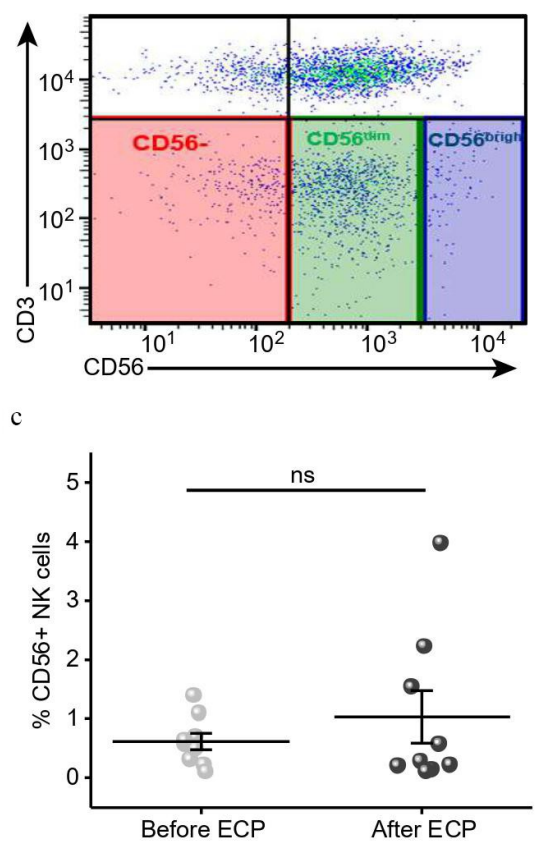

f

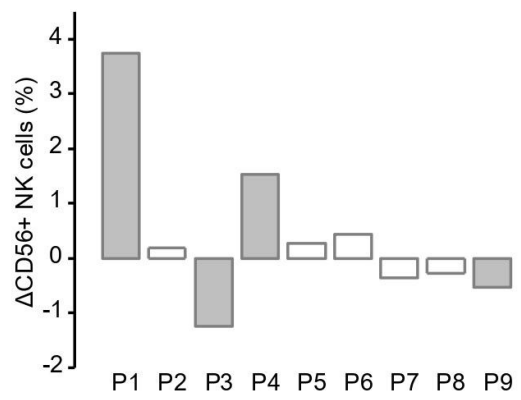

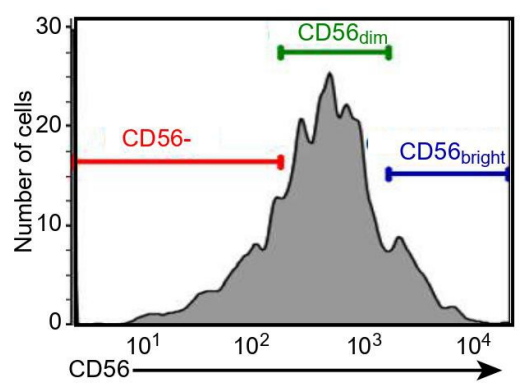

d
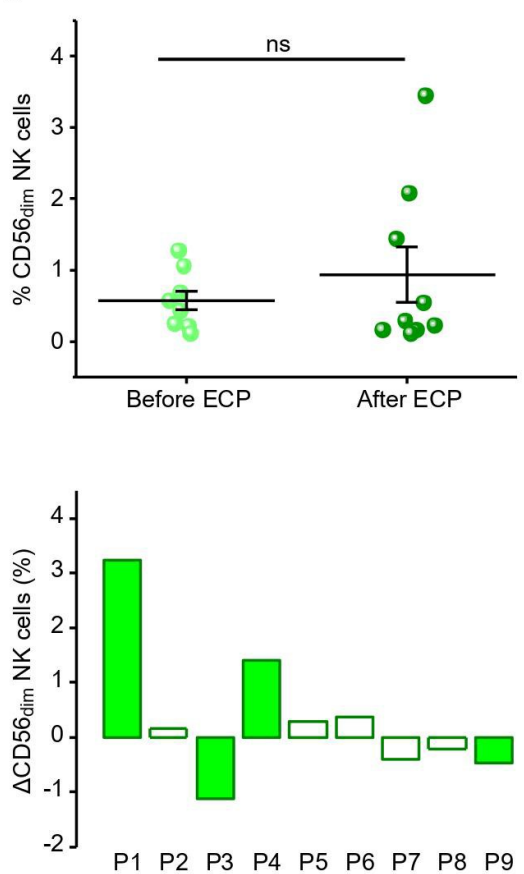
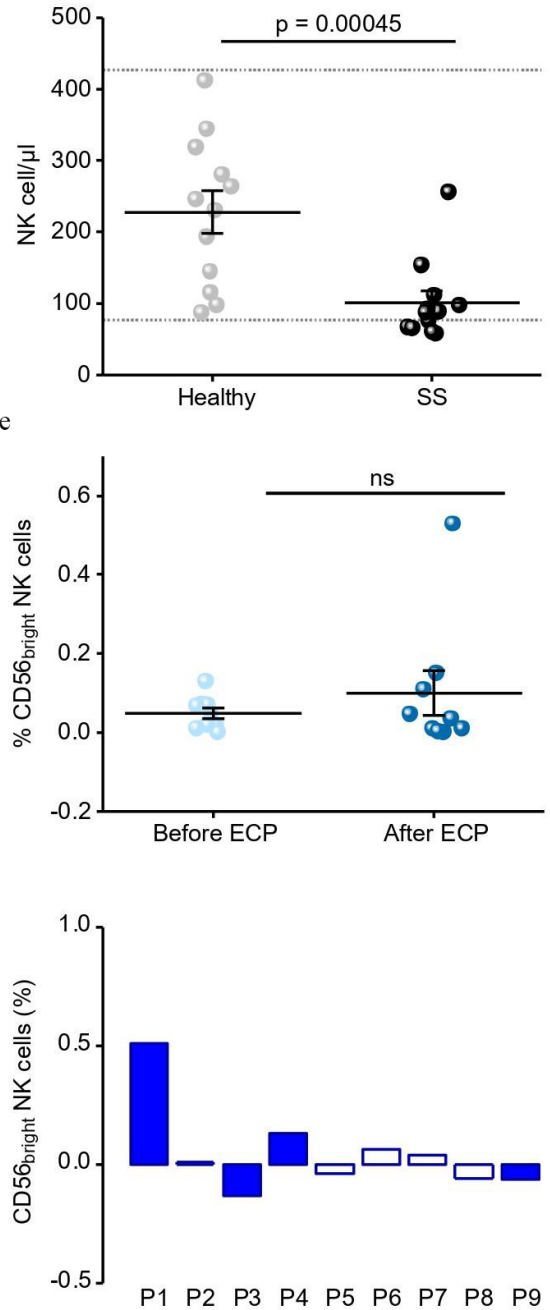

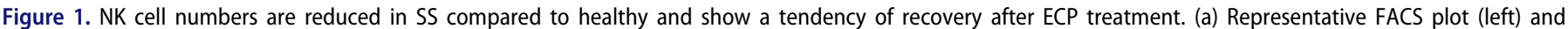

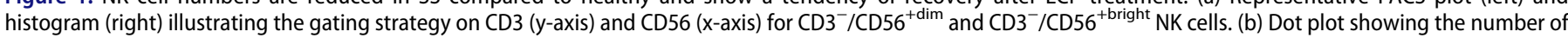

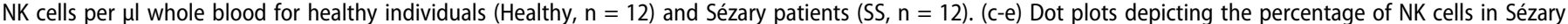

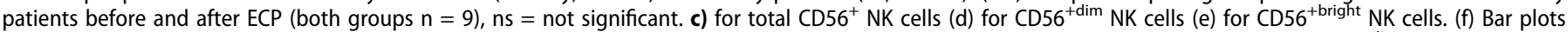

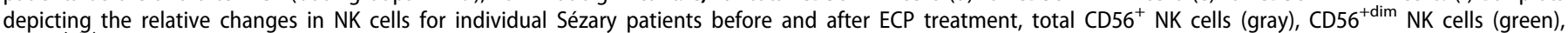
CD56 ${ }^{\text {bright }}$ NK cells (blue). Patients with clinical response to treatment are shown as filled bars, those without as empty bars. 


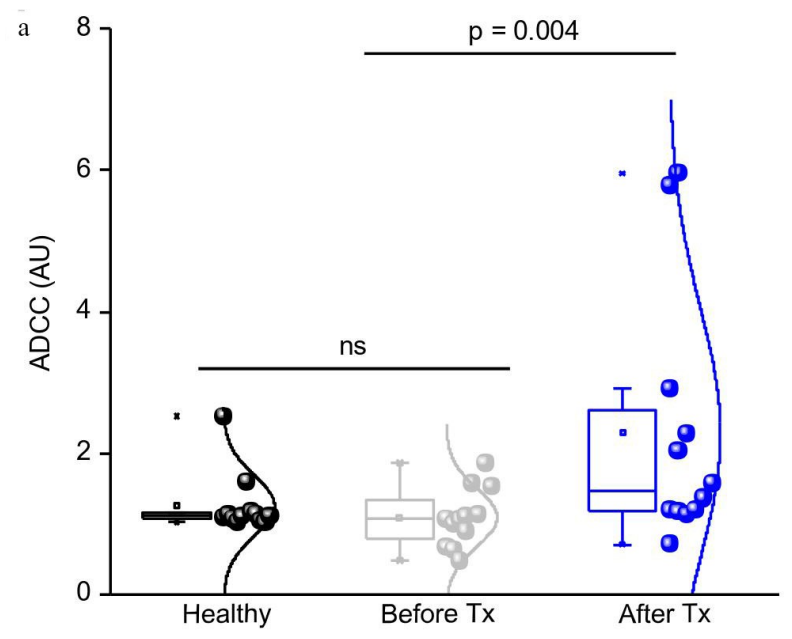

$\mathrm{b}$

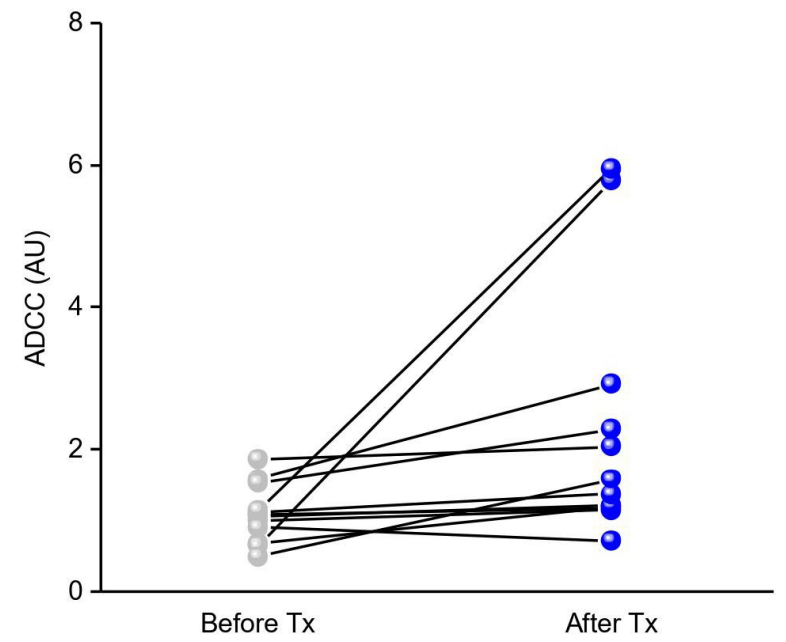

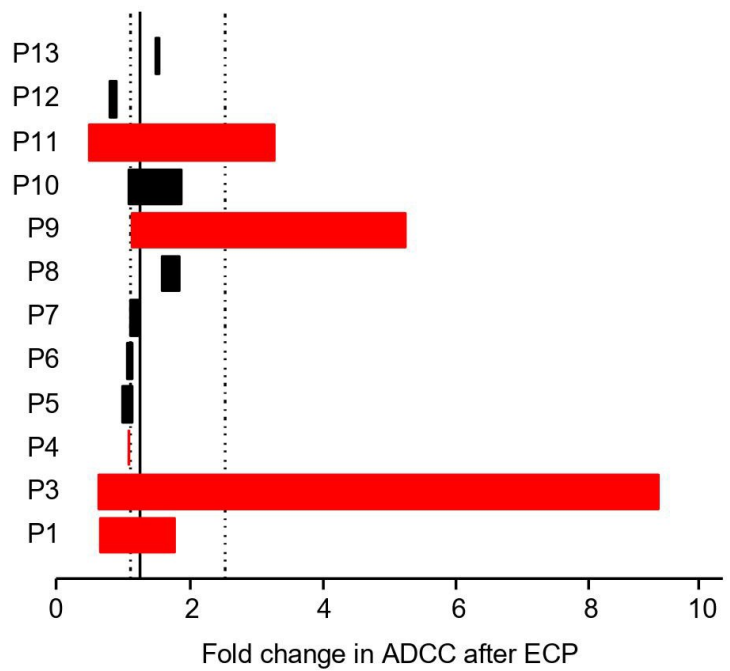

d

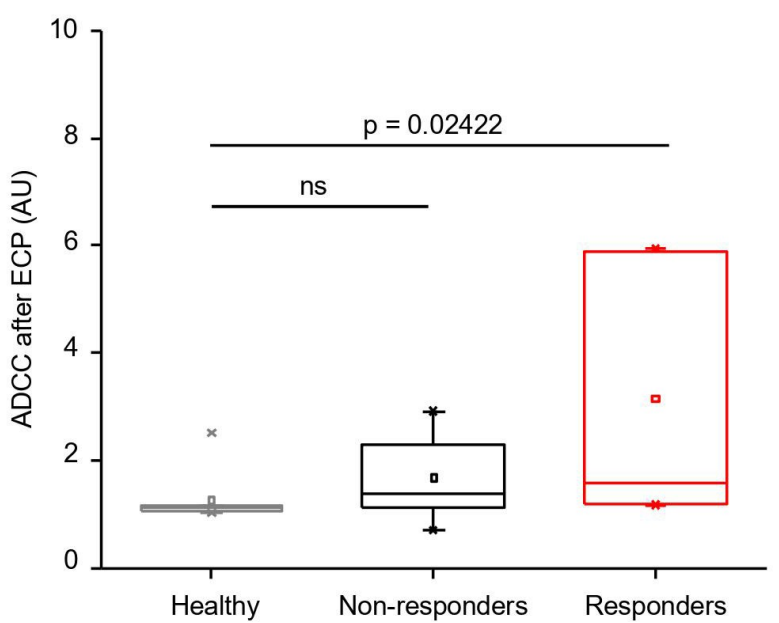

Figure 2. ADCC is enhanced in ECP responders. (a) Boxplots showing the efficacy of antibody-dependent cellular cytotoxicity (ADCC) in arbitrary units (AU) for healthy individuals and Sézary patients before and after ECP treatment (Tx), $\mathrm{n}=12$ for all groups, ns = not significant. A significant increase $(p=.004)$ is detected after ECP therapy. (b) Dot plot presenting the same data as in a) for individual Sézary patients, showing great interpatient variability in response to ECP treatment. (c) Bar plots showing fold changes in ADCC of Sézary patients after ECP treatment. ECP clinical responders in red, non-responders in black. (d) Box plots showing the efficacy of ADCC after ECP in arbitrary units (AU) for healthy individuals and Sézary patients split into non-responders and responders. While the difference in non-reponders in not significant (ns), responders show a significant increase $(p=.02422)$ in ADCC compared to healthy.

ADCC activity after ECP for non-responders did not differ from the ADCC of healthy individuals, but was statistically significantly enhanced in SS patients responding clinically to ECP treatment $(p=.02422)$ (Figure $2 \mathrm{~d}$ ).

\section{Discussion}

ECP is an established and widely used first-line therapy for SS; however, predictive factors and biomarkers for monitoring the response to treatment are yet largely unknown. NK cells and their impact and importance for the mode of action of ECP have recently attracted attention, especially in GvHD and organ transplant rejections, which together with SS constitute the three major approved indications for ECP therapy in Switzerland. ${ }^{9,18,19}$ In CTCL, reduced activity of NK cells has been observed, and increased NK cell numbers upon ECP treatment have been reported, raising the hypothesis of a relative intact immune system being a baseline predictionfactor of response to ECP. ${ }^{9,20}$

Here we demonstrate that NK-mediated ADCC is selectively enhanced in ECP responders and might serve as a reliable biomarker to objectively monitor response to ECP in patients with SS. These findings are strengthened by observations made in patients with GvHD, where low levels of NK cell activity were reported in non-responders and normal NKcell activity before therapy has been proposed as a prognostic marker for response. ${ }^{16}$ We further observed a general tendency of recovery of diminished NK cell subsets in SS patients on long-term treatment, supporting the casuistically reported increase in NK cell numbers in ECP responders. ${ }^{20,21}$ Further, increased NK cells numbers were also detected in one patient with immune-checkpoint-inhibitor-induced colitis, positively influenced by ECP. ${ }^{22}$

Based on our findings and supported by the existing knowledge in the literature, we postulate a vital role of NK cells in 
shaping efficacy of ECP in SS patients and support the use of NK-cell-based therapies for tumor immunotherapy. In general, NK cells are seen as a positive factor in the anti-tumor immune response and their involvement in immune surveillance has been repeatedly demonstrated. ${ }^{17}$ This study broadens the understanding on the role of NK cells' activity in the context of ECP, although the conclusions are limited by the small number of patients and their differences in treatment duration at the time of sampling ranging between 1.5 and 26 months on ECP. Further, we demonstrate enhancement of ADCC, which is exerted typically by $\mathrm{CD} 56^{\mathrm{dim}}$ subset. However, as we only report trends in the quantitative alterations of these cells, the observed increased efficacy may also result from changes in secreted cytokines and paracrine stimulation of ADCC-mediating cells. Consequently, it will be important for future studies to decipher which NK subpopulation - the immature, poorly cytotoxic but cytokine-producing $\mathrm{CD} 56^{\text {bright }}$ or the mature, weakly cytokineproducing, but cytolytic and thus capable of ADCC, CD56 ${ }^{\text {dim }} \mathrm{CD} 16^{+} \mathrm{NK}$ cells determine the efficacy of ECP.

\section{Acknowledgments}

We thank Mitch Levesque and the biobank team of the Department of Dermatology at the University Hospital Zurich for their help to collect and store clinical samples.

\section{Disclosure of Potential Conflicts of Interest}

No potential conflicts of interest were disclosed.

\section{Funding}

This work was supported by the European Molecular Biology Organization [7637]; Schweizerischer Nationalfonds zur Schweizerischer Nationalfonds zur Förderung der Wissenschaftlichen Forschung [PMPDP3_151326]; Swiss Cancer Research Foundation KFS-4243-082017]; Polish National Science Centre [2015/19/B/NZ6/02862]; Forschungskredit of the University of Zurich [FK-15-040]; anonymous Foundation; European Academy of Dermatology and Venereology [PPRC-2019-20]; Jubiläumsstiftung von SwissLife; European Commission Horizon 2020 Programme [692180-STREAMH2020TWINN-2015]; Promedica Stiftung [1406/M and 1412/M]; Clinical Research Priority Program (CRPP) of the University of Zurich as a funder.

\section{ORCID}

Christina Fassnacht (iD http://orcid.org/0000-0001-5379-2687

Mirjam Nägeli (iD) http://orcid.org/0000-0002-2512-2122

Steve Pascolo (iD http://orcid.org/0000-0003-2946-5576

Malgorzata Bobrowicz (D) http://orcid.org/0000-0002-9078-5168

Emmanuella Guenova (iD http://orcid.org/0000-0001-5478-8735

\section{References}

1. Trautinger F, Eder J, Assaf C, Bagot M, Cozzio A, Dummer R, Gniadecki R, Klemke C-D, Ortiz-Romero PL, Papadavid E, et al. European organisation for research and treatment of cancer consensus recommendations for the treatment of mycosis fungoides/ Sezary syndrome - Update 2017. Eur J Cancer. 2017;77:57-74. doi:10.1016/j.ejca.2017.02.027.

2. Scarisbrick JJ, Quaglino P, Prince HM, Papadavid E, Hodak E, Bagot M, Servitje O, Berti E, Ortiz-Romero P, Stadler R, et al. The PROCLIPI international registry of early-stage mycosis fungoides identifies substantial diagnostic delay in most patients. Brit J Dermatol. 2019;181(2):350-357. doi:10.1111/bjd.17258.

3. Mangold AR, Thompson AK, Davis MD, Saulite I, Cozzio A, Guenova E, Hodak E, Amitay-Laish I, Pujol RM, Pittelkow MR, Gniadecki R. Early clinical manifestations of Sezary syndrome: A multicenter retrospective cohort study. J Am Acad Dermatol. 2017;77(4):719-727. doi:10.1016/j.jaad.2017.05.036.

4. Willemze R, Cerroni L, Kempf W, Berti E, Facchetti F, Swerdlow SH, Jaffe ES. The 2018 update of the WHO-EORTC classification for primary cutaneous lymphomas. Blood. 2019;133 (16):1703-1714. doi:10.1182/blood-2018-11-881268.

5. Saulite I, Ignatova D, Chang YT, Fassnacht C, Dimitriou F, Varypataki E, Anzengruber F, Nägeli M, Cozzio A, Dummer R, et al. Blockade of programmed cell death protein 1 (PD-1) in Sezary syndrome reduces Th2 phenotype of non-tumoral $\mathrm{T}$ lymphocytes but may enhance tumor proliferation. Oncoimmunology. 2020;9(1):1738797. doi:10.1080/ 2162402X.2020.1738797.

6. Bobrowicz M, Fassnacht C, Ignatova D, Chang YT, Dimitriou F. Guenova E. Pathogenesis and therapy of primary cutaneous T-Cell Lymphoma: collegium internationale allergologicum (CIA) update 2020. Int Arch Allergy Immunol. 2020;181(10):733-745..

7. Guenova E, Watanabe R, Teague JE, Desimone JA, Jiang Y, Dowlatshahi M, Schlapbach C, Schaekel K, Rook AH, Tawa M, et al. TH2 cytokines from malignant cells suppress TH1 responses and enforce a global TH2 bias in leukemic cutaneous T-cell lymphoma. Clin Cancer Res. 2013;19(14):3755-3763. doi:10.1158/1078-0432.CCR-12-3488.

8. Molloy K, Jonak C, Woei AJF, Guenova E, Busschots AM, Bervoets A, Hauben E, Knobler R, Porkert S, Fassnacht C, et al. Characteristics associated with significantly worse quality of life in mycosis fungoides/Sézary syndrome from the prospective cutaneous lymphoma international prognostic index (PROCLIPI) study. Br J Dermatol. 2020;182(3):770-779. doi:10.1111/bjd.18089.

9. Knobler R, Arenberger P, Arun A, et al. European dermatology forum: Updated guidelines on the use of extracorporeal photopheresis 2020-Part 2. J Eur Acad Dermatol. 2020.

10. Alfred A, Taylor PC, Dignan F, El-Ghariani K, Griffin J, Gennery AR, Bonney D, Das-Gupta E, Lawson S, Malladi RK, et al. The role of extracorporeal photopheresis in the management of cutaneous T-cell lymphoma, graft-versus-host disease and organ transplant rejection: a consensus statement update from the UK Photopheresis Society. Br J Haematol. 2017;177(2):287-310. doi:10.1111/bjh.14537.

11. Sanyal S, Child F, Alfred A, Callaghan T, Alband N, Whittaker S, Cowan R, Parry E, Robinson S, Dunnill MGS, et al. U.K. national audit of extracorporeal photopheresis in cutaneous T-cell lymphoma. Br J Dermatol. 2018;178(2):569-570. doi:10.1111/ bjd.15871.

12. Olsen E, Vonderheid E, Pimpinelli N, Willemze R, Kim Y, Knobler R, Zackheim H, Duvic M, Estrach T, Lamberg S, et al. Revisions to the staging and classification of mycosis fungoides and Sezary syndrome: a proposal of the International Society for Cutaneous Lymphomas (ISCL) and the cutaneous lymphoma task force of the European organization of research and treatment of cancer (EORTC). Blood. 2007;110(6):1713-1722. doi:10.1182/ blood-2007-03-055749.

13. Olsen EA, Whittaker S, Kim YH, Duvic M, Prince HM, Lessin SR, Wood GS, Willemze R, Demierre M-F, Pimpinelli $\mathrm{N}$, et al. Clinical end points and response criteria in mycosis fungoides and Sezary syndrome: a consensus statement of the International society for cutaneous lymphomas, the United States cutaneous lymphoma consortium, and the cutaneous lymphoma task force of the european organisation for research and treatment of cancer. J Clin Oncol. 2011;29 (18):2598-2607. doi:10.1200/JCO.2010.32.0630.

14. Belizaire R, Kim HT, Poryanda SJ, Mirkovic NV, Hipolito E, Savage WJ, Reynolds CG, Fields MJ, Whangbo J, Kubo T, et al. Efficacy and immunologic effects of extracorporeal photopheresis plus interleukin-2 in chronic graft-versus-host disease. 
Blood Adv. 2019;3(7):969-979. doi:10.1182/ bloodadvances.2018029124.

15. Iniesta $\mathrm{P}$, Revilla $\mathrm{N}$, Chen-Liang $\mathrm{TH}$, Hurtado AM, Vicente V, Heras I, Jerez A, Lozano ML. An early increase of CD56 bright natural killer subset as dominant effect and predictor of response to extracorporeal photopheresis for graft-versus-host disease. Transfusion. 2018;58(12):2924-2932. doi:10.1111/trf.14964.

16. Rook AH, Suchin KR, Kao DM, Yoo EK, Macey WH, DeNardo BJ, Bromely PG, Geng Y, Junkins-Hopkins JM, Lessin SR, et al. Photopheresis: clinical applications and mechanism of action. J Investig Dermatol Symp Proc. 1999;4(1):85-90. doi:10.1038/sj. jidsp.5640188.

17. Chiossone L, Dumas PY, Vienne M, Vivier E. Natural killer cells and other innate lymphoid cells in cancer. Nat Rev Immunol. 2018;18(11):671-688. doi:10.1038/s41577-018-0061-z.

18. Ni M, Wang L, Yang M, Neuber B, Sellner L, Hückelhoven-Krauss A, Schubert M-L, Luft T, Hegenbart U, Schönland S, et al. Shaping of CD56(bri) natural killer cells in patients with steroid-refractory/ resistant acute graft-vs.-Host disease via extracorporeal photopheresis. Front Immunol. 2019;10:547. doi:10.3389/ fimmu.2019.00547.

19. Regierung DPdS. 832.112.31 Verordnung des EDI über Leistungen in der obligatorischen Krankenpflegeversicherung. 2020; https:// www.admin.ch/opc/de/classified-compilation/19950275/index. html. Accessed 222020

20. Prinz B, Behrens W, Holzle E, Plewig G. Extracorporeal photopheresis for the treatment of cutaneous T-cell lymphoma-the Dusseldorf and Munich experience. Arch Dermatol Res. 1995;287 (7):621-626. doi:10.1007/BF00371732.

21. Yoo EK, Cassin M, Lessin SR, Rook AH. Complete molecular remission during biologic response modifier therapy for Sezary syndrome is associated with enhanced helper $\mathrm{T}$ type 1 cytokine production and natural killer cell activity. J Am Acad Dermatol. 2001;45(2):208-216. doi:10.1067/mjd.2001.116345.

22. Apostolova P, Unger S, von Bubnoff D, Meiss F, Becher B, Zeiser R. Extracorporeal photopheresis for colitis induced by checkpoint-inhibitor therapy. N Engl J Med. 2020;382 (3):294-296. doi:10.1056/NEJMc1912274. 